\title{
Dados hematológicos do cão adulto normal (*)
}

\author{
por \\ W. O. Cruz, E. M. da Silva e R. Pimenta de Mello \\ (Com uma figura no texto)
}

O cão é o animal indicado para estudos hematológicos. As características que o tornam animal de escolha são:

a) Porte. Os métodos hematológicos de rotina requerem para se trabalhar com comodidade 1 a $2 \mathrm{~cm} .{ }^{3}$ diários de sangue. No cão cujo peso médio é de 10 quilos, $1 \mathrm{~cm} 3$ representa $0,1 \%$ de seu volume sanguíneo total. Esta quantidade de sangue retirada diariamente não afeta, na prática, a fisiologia hemática dêstes animais. Também quando é necessário a retirada repetidas vêzes ou de grandes quantidades de sangue consegue-se fazề-lo fàcilmente usando suas calibrosas e superficiais veias jugulares, faceis de atingir na grande maioria dêsses animais. O cão não é animal muito sensível à retirada de grande quantidade de sangue podendo perder de um só vez até mesmo $40 \%$ de seu volume total de sangue.

b) Tipo de alimentação. Sendo um animal onívoro pode-se nele experimentar os mais variados tipos de alimentação nos processos regenerativos e degenerativos do sangue. Adapta-se com grande facilidade ao regime de uma só alimentação por dia cuja ingestão é geralmente feita em curto prazo o que facilita os estudos de metabolismo, pelo contrôle fácil das quantidades ingeridas. Também adaptarse com extrema rapidez a mudança brusca de regime alimentar. Após ligeiro treinamento pode aprender a evacuar em hora determinada mediante a simples retirada da gaiola. Para estudos de metabolismo da hemoglobina as quantidades de urina e fézes emitidas diariamente permitem a execução fácil das várias provas necessárias.

( $\left.{ }^{\star}\right)$ Trabalho da Seção de Hematologia auxiliada por benemerência do Dr. Guilherme Guinle.

* Recebido para publicação a 17 de Maio de 1945 . 
c) Resistência natural às infecções. O cão é animal extremamente resistente à infestações pelos germes piogênicos.

Com assepcia parcial, feridas operatórias, mesmo de consideraveis extensões, cicatrizam em segunda intenção, observando-se raramente infecção intercorrente. Esta resistência aliada ao porte torna possivel tôda sorte de processos operatórios experimentais.

d) Docilidade. O cão ràpidamente se habitua à técnica de colheita de material e ao cativeiro. Animal fácil de mansear, salvo raras exceções verificadas em alguns animais de comportamento pràticamente anormal, o qual se caracteriza por violenta reação ao serem conduzidos para a colheita de material.

Os cães cujos exames são apresentados neste trabalho foram cedidos ao Instituto pelo Serviço de Assistência Veterinária da Prefeitura do Distrito Federal. A grande maioria dos animais capturados se apresentam em bom estado de nutrição e aspecto geral. 'Êsse fato é explicado por tratar-se de animais pertencentes a moradores dos subúrbios pobres da cidade e por serem capturados quando surpreendidos em fuga da residência de seus donos. A restituição do animal apreendido só pode ser feita mediante pagamento de multa e em prazo relativamente curto, justificando-se dessa maneira a aparente falta de interêsse dos donos.

A maioria são animais adultos e de raça impura. Foram eliminados cães muito jovens ou senecentes.

Colheita de sangue: Os cães são colocados em goteiras de ClaudeBERNARD e a contenção é feita com fita dẹ cadarço que prende as patas numa das extremidades e a outra fixa nas ranhuras laterais da goteira. Raspa-se o pescoço dos dois lados com máquina de cortar cabelos, acompanhando os bordos dos músculos externo-cleido-mastoideos. Estirada a pela comprimida com o dedo polegar a região próxima da clavícula as jugulares ficam salientes, facilitando extremamente a punção venosa (foto 1 ). O sangue é retirado da jugular com agulha apropriada $(30 \times 12)$ em seringa sêca e imediatamente colocado em pequenas garrafas de $4 \mathrm{~cm} 3$ de capacidade, marcadas para $2 \mathrm{~cm} 3$, contendo mistura de oxalatos em pó. As garrafas para $2 \mathrm{~cm} 3$ de sangue são preparadas da seguinte maneira: $0.08 \mathrm{~cm} 3$ de uma solução de oxalato de amônio, $3 \mathrm{gm}$, oxalato de potássio $2 \mathrm{~g}$ para $100 \mathrm{~cm} 3$ de água distilada são colocados em cada garrafa e deixadas em estufa a $38 .^{\circ}$ até completa secagem. Assim, se obtém a correta relação de $20 \mathrm{mg}$. dos oxalatos 
reunidos para $1 \mathrm{~cm} 3$ de sangue. Todos os exames hematclógicos são executados no máximo 3 horas depois da colheita. (Foto 1).

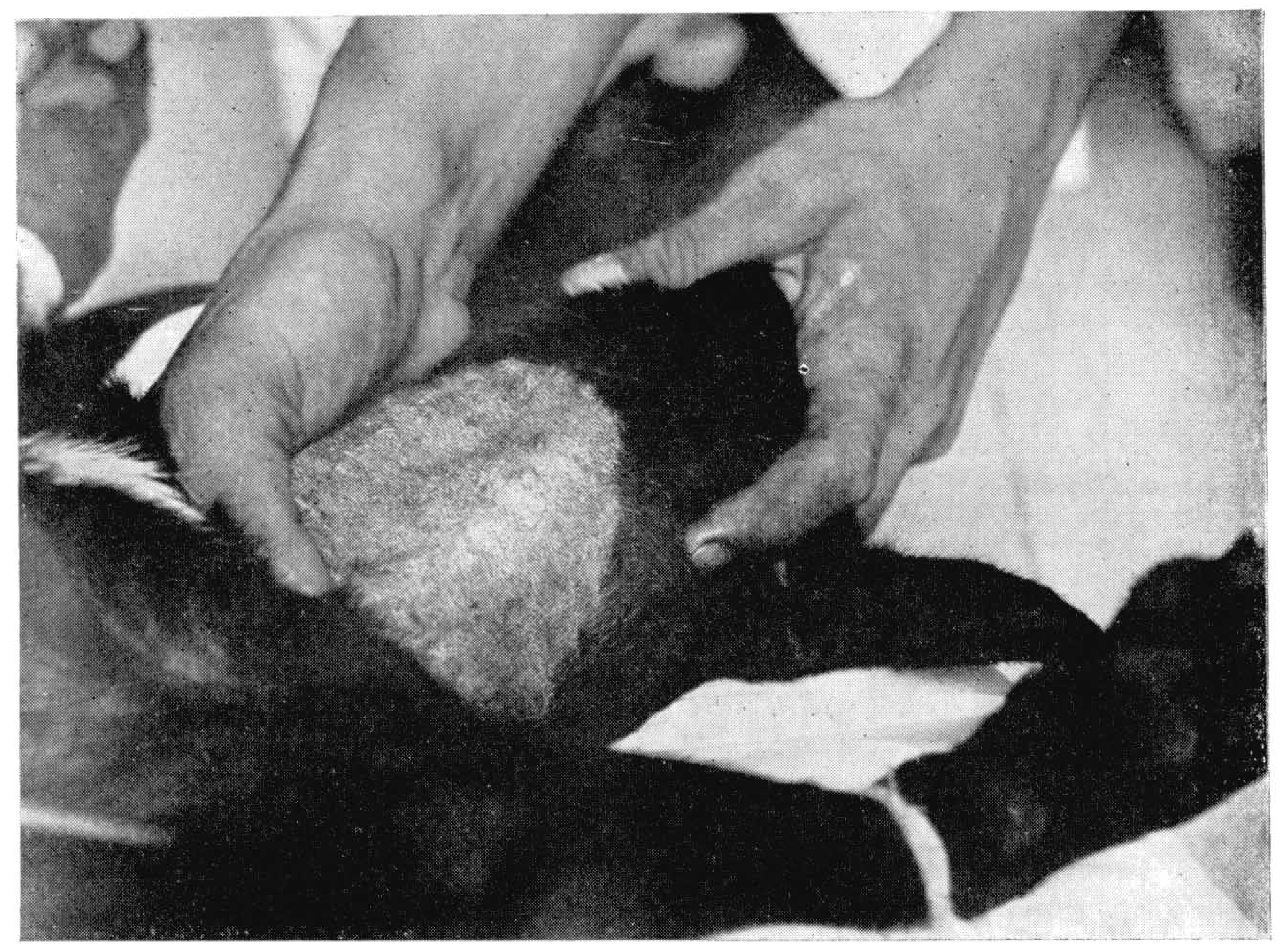

Fig. 1

Posição adequada afim de tornar saliente a jugular para facilidade da punção e colheita de sangue

\section{DETERMINAC̣̃̃O DOS ELEMENTOS DA SÉRIE VERMELHA}

Contagem de hemátias. Dilue-se o sangue 1/200 em pipeta de Thома, usando como líquido diluidor solução de cloreto de sódio a 8.5 o/oo. Depois de convenientemente agitado coloca-se uma gôta na câmara de Neubaer e verifica-se se as hemátias estão uniformemente distribuidas ao acaso na câmara, o que é indispensável. Esta câmara fabricada por Spencer \& Co. caracterizada pela presença de linhas brilhantes no retículo constituiu um aperfeiçoamento bastante útil. Contam-se as hemátias contidas em 5 grupos de 16 quadradinhos de $1 / 400 \mathrm{~mm} 2$ de superfície assinalando cada hemátia com pressão digital num contador automático de unidades. Êste processo facilita o trabalho por evitar o cálculo e cansaço mental do ato de enumerar as hemátias. De fato, contando-se 80 quadrículas a fórmula para se ter o número de hemátias por mm3 fica reduzida a uma simples multiplicação do número 
obtido no contador automático pela constante 10000 . Esta constante 10000 é o resultado das operações indicadas entre parentesis na fórmula empregada: $N\left(\frac{200 \times 10 \times 400}{80}\right)$, sendo N o número de hemátias obtidas no contador automático. Exemplo: suponhamos que se tenha contado 500 hemátias, o cálculo será $500 \times 10000$ - 5000000 por mm3. Um artifício aconselhado para diminuir o cansaço muscular da mão é o de acionar o contador 1 vez para 2 hemátias vistas, multiplicando-se por 2 o resultado final no contador automático.

Em contraste às dificuldades assinaladas para uma correta contagem de hemátias, a determinação da hemoglobina e do hematócrito são na prática pouco sujeitas a êrro e ambas possuem uma precisão razoável para métodos biológicos. Assim, fácil nos será constatar qualquer senão na execução dos métodos hematológicos pela interdependência que deverá sempre existir pelos valores fornecidos por cada um: exemplo: um sangue retirado de cão normal mostrou: hematócrito $42 \%$, hemoglobina $12.5 \mathrm{~g}$. e hemátias 4 milhões. Os característicos numéricos das hemátias dêsse sangue são: Volume 105 u3; Hemoglobina por hemátias 31yy e concentração de hemoglobina por hemátia 30\%. Dois dêsses resultados são exageradamente elevados e pọ isso anômalos: o volume de hemátias do cão raramente atinge 80 u3 e a quantidade de hemoglobina excepcionalmente atinge 26yy. A concentração de hemoglobina, entretanto, apresenta-se inteiramente normal $(30 \%)$. Êstes dados indicam que os valores empregados para obtenção da concentração média de hemoglobina por hemátia estão mui possivelmente corretos, enquanto que os dados empregados na obtenção do volume e da quantidade de hemoglobina por glóbulo estão sujeitos a revisão. Ora, a concentração é obtida pela relação hb/hemat. cujas determinações devem estar corretas, como vimos acima; o volume é obtido pela relação hemat/ht e o conteúdo pela relação hb/ht e como estas relações apresentaram números elevados indicam que houve um êrro para menos na contagem de glóbulos.

'Êsse é o motivo pelo qual são criticáveis aquêles métodos de registro fotográfico da célula de Neubauer para contagem posterior. Se acaso haja êrro de diluição ou qualquer outro fator que motive uma distribuição anormal das hemátias as determinações hematológicas do caso ficarão perdidas, o que não acontece se obtivermos os dados hematológicos no mesmo dia da retirada do sangue e só o aceitarmos após o contrôle dos mesmos, verificando suas reciprocas relações, como acima exemplificamos. 
Dosagem de hemoglobina: A dosagem colorimétrica da hemoglobina transformando esta substância em cloridrato de hematina teve sua justificativa no fato de ser o aparelho visual pouco sensivel ao vermelho, dificultando a constatação de variações apreciáveis da substância. Êsse método apresenta um inconveniente sério originado de um detalhe importante não assinalado na maioria dos autores e geralmente descurado na prática, ocasionando erros grosseiros. Êste detalhe consiste no seguinte: a transformação da hemoglobina em cloridrato de hematina se processa em prazo médio de 30 minutos à temperatura ambiente. Em condições diversas não há completa transformação da substância, verificando-se o desenvolvimento incompleto da côr motivando erros apreciáveis (1).

Com a aplicação dos métodos de dosagem da hemoglobina sob a forma de oxi-hemoglobina no espectrofotometro de Pulfrich ou nos colorimetros foto-elétricos, cujas técnicas descrevemos adiante, não mais se justifica o emprêgo do hemoglobinômetro de SaHLi e outros aparelhos baseados na dosagem da hemoglobina na forma de cloridrato de hematina. Além da causa de êrro assinalada, temos de acrescentar a decorrente do êrro pessoal do observador e considerar o fator tempo dispendido nas dosagens. O emprêgo do espectrofotômetro de Pulfrich ou dos colorímetros foto-elétricos (LeITZ, KLETT-Summerson etc.), permite, como veremos, a dosagem com amostras pequenas do sangue, a sua realização em tempo curto $(2$ minutos em média desde a pipetagem à leitura no colorimetro), como também se pode deixar para proceder a leitura algumas horas depois de preparada a solução.

O fator pessoal, motivado pelos graus diversos de sensibilidade à intensidade luminosa, êrro inerente a todos colorimetros de comparação visual, é abolido nos colorímetros foto-elétricos.

Técnica: 20 milimetros cúbicos de sangue são aspirados em pipeta especialmente calibrada, colocados em tubo de hemólise contendo $1,98 \mathrm{~cm} 3 \mathrm{de}$ água destilada alcalinisada pelo carbonato de sódio a $1 \%$ oo ou amônia a $4 \%$ quando se usa o espectrofotometro de Pulfrich. Empregando o colorimetro foto-elétrico de Leitz a quantidade de solução alcalizada é $4 \mathrm{~cm} 3$. Aspirado o sangue, limpa-se com papel de filtro a parte exterior da pipeta e faz-se a solução.

Detalhe importante a ser observado é o referente a sangues apresentando grandes leucocitoses ou causas que tornem turva a solução. Deve-se, então, centrifugar 5 a 10 minutos a 2000 rotações antes de proceder a leitura.

A técnica de dosagem pelo espectofotômetro de Pulfrich é uma modificação do processo de Heilmeyer (2), a qual consistiu na substituição da 
lâmpada a vapor de mercúrio (HAGEPHot) pela lẩmpada fotométrica e emprêgo de água destilada como substância de comparação. O aparelho foi padronizado pela determinação do ferro hemático pelo processo de WONG (3), sabendo-se que em 1 grama de hemoglobina há $3,35 \mathrm{mg}$ de ferro.

Toma-se a solução de hemoglobina preparada como acima está descrito e coloca-se em cuba de $2,5 \mathrm{~mm}$ de espessura e compara-se com água destilada. A leitura é feita com o filtro S 57 . Na prática, basta multiplicar o valor numérico da extinção (escala em vermelho do tambor do aparêlho) pela constante 25 obtida no estabelecimento da curva de hemoglobina. Assim, por exemplo, sendo a leitura 0,50 , o resultado final será $0.50 \times 25=12.50 \mathrm{~g}$ em $100 \mathrm{~cm} 3$ de sangue. Êste método tem o limite de êrro de $\pm 0.50 \mathrm{gr}$.

O colorimento foto-elétrico de Leitz Mass e o de Klett-Summerson vêm acompanhados de uma tabela com a quantidade de hemoglobina correspondente às diversas extinções. $O$ aparelho que usamos é de escala logsrítmica e foi padronizado pelo espectrofotômetro de Pulfrich encontrando-se valores pràticamente idênticos. $O$ filtro usado é o filtro verde ( $F$ 401). A curva de êrro deste método é de \pm 0.525 , significando que uma variação de mais ou menos meia grama pode correr por conta do êrro do método.

Chamamos a atenção para um detalhe técnico de grande importância quando se dosa hemoglobina de sangue anêmico ou policitêmico: todo aparelho de comparação de côr tem uma precisão maior em uma região média de leitura, devendo-se evitar as regiões extremas o que se consegue aumentando a quantidade da amostra de sangue em casos de anemia e diminuindo nos de policitemia. No espectrofotômetro de Pulfrich para dosagem de $\mathrm{Hb}$ aconselha-se ler entre as extinções de 0,30 a 0,60. No colorímetro de LEITzMass com escala logaritímica a leitura aconselhável é entre 75 e 90 de absorção.

\section{HEMOGLOBINA POR CENTO E HEMOGLOBINA EM GRAMAS}

Wintrobe (4) em seu moderno tratado de Hematologia refere-se a êsse tema de modo bem explícito.

A apresentação de resultado em "por cento" tem tôda sorte de inconvenientes:

a) dosagem de hemoglobina de animais normais do mesmo sexo distribui-se, como todo fenômeno biológico, numa aproximada curva de Gauss. A rigor, não se pode considerar os valores extremos dessa curva como anormais e, assim, tomar a média dos resultados como cifra ncrmal $(100 \%)$ 
maneira empirica de simplificar indevidamente a questão. $O$ valor médio normal em gramas deverá ser sempre acompanhado da medida de dispersão da curva (desvio padrão) e um resultado só poderá ser considerado anormal caso se apresente três vêzes êste desvio padrão;

b) A hemoglobina normal difere, em alguns animais, com o sexo e a idade; $e$

c) O número tomado como $100 \%$ varia com os autores (13.8 até 21.0 ) em virtude do emprêgo de métodos diversos como padrão.

O método mais preciso para dosagem de hemoglcbina é aquêle que determina o poder combinatório de oxigênio do sangue. A rigor, a hemoglobina deveria ser sempre indicada por volumes por cento dessa capacidade combinatória. Como seria de pouco valor prático os hematologistas modernos preferiram aceitar o trabalho de HuEFnER, 1894 (4) observanda que 1 grama de hemoglobina combina-se com $1,338 \mathrm{~cm} 3$ de oxigênio em condições normais de temperatura e pressão. Pela dificuldade de se obter uma hemoglobina estável e pura esta observação não foi ainda confirmada, mas não há nenhum inconveniente em tomar êsse dado como correto para fins de padronização. Por esses motivos foi aconselhado exprimir os resultados de hemoglobina em grama por $100 \mathrm{~cm} 3$ de sangue.

Hematócrito: Para obtermos a relação entre o plasma e os glóbulos, usamos o micro hematócrito de Van Allen, (5) o único que permite o emprêgo de pequenas quantidades de sangue. O líquido diluidor empregado é solução de oxalato de sódio a $1.3 \%$. Aspira-se o sangue até a marca 100 do aparelho e a seguir a solução de oxalato até aproximadamente $2 / 3$ da ampola. Coloca-se o clipe, centrifuga-se, a seguir, a 3.500 rotações durante 30 minutos. A centrifugação deve ser completa, o tempo a se empregar variando na proporção inversa do diâmetro médio da hemátia. A hemátia do cão, como a do homem, bastam 30 minutos, enquanto que as hemátias de carneiro ou cabra requerem cêrca de 45 minutos. Um mínimo de 2 hematócritos deve ser feito para cada amostra de sangue. Um detalhe importante a ser cbservado refere-se á condição de estabilidade do líquido diluidor: uma maior ou menor concentração de oxalato reflete-se sôbre o volume de hemátia. Sabe-se que a hemátia funciona como um sensivel osmômetro, sofrendo o seu volume apreciáveis variações com pequenas mudanças de concentração da solução que a envolve. Assim, o oxalato deve ser cuidadosamente sêco e pesado e a solução guardada em frasco com rôlha de esmeril. Convém não usar mais de uma semana a solução oxalatada: por isso é aconselhável preparar pequenas porções de cada vez. Havendo cuidado no preparo e con- 
servação dessa solução é a determinação do hematócrito uma das medidas hematológicas de menor probabilidade de êrro.

O hematócrito também permite um contrôle grosseiro do número de leucocitos: uma divisão corresponde "grosso modo" a 15000 leucocitos por mm3. Em casos de leucocitose esta medida é muito útil para o contrôle da contagem dos glóbulos brancos na câmara de Neubauer.

Tratando-se de sangue sabidamente leucêmico é conveniente fazer a diluição na solução de oxalato, deixar sedimentar durante 15 a 30 minutos e depois então centrifugar. Obtém-se, assim, uma mais nítida separação entre as camadas de hemátias e leucocitos.

Uma impressão grosseira da quantidade de leucocitos pode ser obtida deixando sedimentar a garrafinha com sangue cxalatado durante 1 hora. A çexpressura da camada de leucocitos é diretamente proporcional ao número desses elementos.

Quando se trabalha com quantidade maiores de sangue uma precisão ainda maior é obtida usando-se o hematócrito de Wintrobe (6).

Não há necessidade de líquido diluidor. Coloca-se o sangue oxalatado na aparelho até a marca 10 e centrifuga-se 30 minutos a 3.500 rotações.

Para quantidades grandes de sangue devem ser usados tubos de centrifugação de capacidade de $20 \mathrm{~cm} 3$ especialmente graduados para essa deter minação. Não há necessidade de líquido diluidor, colocando-se o sangue oxalatado até a marca 10 ou 20 e centrifugando-se 30 minutos a 3500 rotações por minuto. Deve-se usar também 2 tubos para cada sangue, o mesmo sendo aconselhado trabalhando com o hematocrito de Wintrobe.

\section{CARACTERES DA HEMÁTIA (Indices Qualitativos da Hemátia)}

Sabendo-se o volume e o conteúdo de hemoglobina de determinado número de hemátias pode-se obter o volume médio e a quantidade média de hemoglobina de uma hemátia. A relação entre êstes dois dados nos dará a concentração de hemoglobina em relação aos outros constituintes da hemátia.

A obtenção dessas medidas tem uma dupla e importante finalidade: contrôle das determinações hematológicas referentes à série vermelha (numeração de hemátias, dosagem de hemoglobina e determinação do hematocrito) e informações muito úteis sôbre o tipo de uma anemia, dado êste que fornece indicações sôbre sua etiologia e tratamento.

Das determinações hematológicas a que apresenta maiores probabilidades de erro é, sem dúvida, a contagem de hemátias. Várias são as causas de 
êrro que influem na obtenção dêsses dado: a distribuição das hemátias na amostra de sangue utilizada, a pipetagem, a agitação e distribuição na pipeta de Thoma, a distribuição na câmara de Neubauer.

O número de hemátias contadas na câmara tem grande importância para a precisão da medida. Para 500 hemátias o êrro padrão desta medida é $\pm 4 \%$; para 1000 células $\pm 3.2 \%$; para $2000-2.3 \%$; para $4000-1.6 \%$ e, finalmente para $8000-1.1 \%$. (7) $\mathrm{Na}$ prática tanto para uso clinico como para pesquisas hematológicas é hábito contar-se unicamente 500 hemátias. Por conseguinte, valores significativos devem ser maiores três vezes o êrro padrão. Assim, para uma contagem de cinco milhões de hemátias por mm3 só resultados de \pm 500000 por mm3 podem ser considerados significativos. Quando se deseja medida exata um número maior de hemátias deve ser contado, (acima de 1000 ) e a distribuição em cada quadrícula observada de maneira que se possa verificar pela comparação entre a curva de distribuição dêstes dados e a curva teórica de Gauss.

Caso repetidas determinações revelem que de fato as características das hemátias se encontram modificadas pcderemos com estes dados classificar algumas discrasias sanguineas.

Em anemias ferro-carenciais as hemátias apresentam um volume e conteúdo de hemoglobina menores que o normal. Esta última de modo mais acentuado, o que vem significar uma concentração hemoglobínica abaixo do normal. A diminuição dêsses valores tende para um determinado nivel o qual caracteriza os graus mais avançados de microcitose a hipocromia encontrados nas anemia ferro-privas.

No homem em casos de anemia perniciosa o volume e conteúdo de hemoglobina acham-se acima do normal. Como esses aumentos guardam a mesma proporção entre si a concentração hemoglobínica permanece normal nestes casos.

Em muitos discrasias do sangue humano tiveram êsses dados aplicação prática, como nas anemias da malária, sprue, icterícia hemolítica, hemorragias agudas, etc.

Observações periódicas dêsses valores característicos da hemátia média durante o decurso do tratamento nos permite acompanhar a progressiva normalização do sangue e assim controlar a potência dos preparados ou suas doses adequadas.

Contagem de reticulocitos: Dcs métodos descritos para contagem de reticulocitos o mais prático e também o mais preciso é aquêle que aconselha observar à fresco sangue misturado ao azul hrilhante cresil. Prepara-se bri- 
lhante cresil pulverisando em gral $0.2 \mathrm{~g}$ do corante e dissolvendo em $100 \mathrm{~cm} 3$ de uma solução de cloreto de sódio a 0.6 \%

Obtem-se, assim, uma solução final pràticamente isotônica com o plasma, de importância fundamental neste método. A solução deve ser duas vêzes filtrada e guardada em vidro bem fechado para evitar evaporação e conseqüênte mudança de tonicidade. Misturarse esta solução a sangue em partes iguais em tubo de hemólise ou coloca-se e mistura-se diretamente uma geta de cada entre lâmina e lamínula. Observa-se ao microscópio com lente de imersão, notando-se a relação entre hemátias com substâncias retículo filamentosa e as demais. E' suficiente contar 500 a 1000 hemátias. Como geralmente a determinação de reticulocitos não é sempre acompanhada da numeração de hemátias usa-se expressar o resultado em por cento.

Medida da resistência globular: A medida da resistência globular é de importância em estudos experimentais.

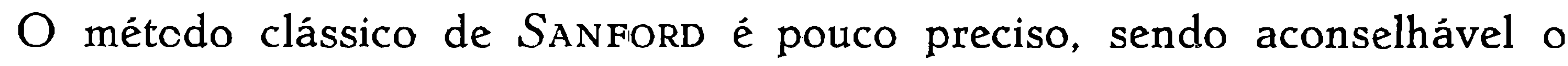
método de Hunter (8) que consiste no seguinte:

Toma-se uma série de tubos cada um contendo solução de clorêto de sódio de concentrações diferentes $(0.50,0.46,0.42,0.38 \%$ etc. ) e um contendo água distilada. Coloca-se em cada tubo a mesma quantidade de sangue agita-se suavemente para uma perfeita mistura e decorridos 5 minutos centrifuga-se, devemos chamar a atenção de que o fenomeno da hemólise "in vitro" se processa com extrema rapidez, sendo desnecessário, portanto, esperar um tempo mais longo para a leitura. O sobrenadante é transferido para as cubas do colorimetro foto-elétrico e procedida a leitura. Toma-se a leitura do tubo de água destilada como $100 \%$ e sôbre êste resultado calcula-se a percentagem de hemólise dos demais tubos. Constrci-se uma curva tendo como abcissa a percentagem de hemólise e como ordenada as concentrações das soluções de cloreto de sódio. Trabalhando-se com o colorimetro foto-elétrico de LeItZ-MASS obtem-se bons resultados empregando-se $0,02 \mathrm{~cm} 3$ de sangue e $4 \mathrm{~cm} 3$ de líquido em cada tubo. No cão normal a hemólise se inicia nas soluções $0,48 \%$ de cloreto de sódio e é completa entre 0,30\%. Diminuindo-se a quantidade de líquido diluidor para $2 \mathrm{~cm} 3$ pode-se proceder as leituras no espectrofotômetro de Pulfrich e construir a curva de hemólise da maneira já indicada.

Dois detalhes técnicos são de grande importância nessa determinação: oxigenação do sangue e emprêgo de amostra recentemente colhida. Com efeito, Whithy \& Hynes (9) obtiveram curvas extremamente diversas traba lhando com sangue vencso, arterial ou saturado de dióxido de carbono. 
$\mathrm{Na}$ prática obtém-se uma suficiente e rápida oxigenação do sangue agitando o recipiente ao ar durante 2 a 5 minutos. Deve-se trabalhar com amostras recentemente colhidas pois uma ligeira hemólise já é observada decor ridas 24 a 48 horas, mesmo conservando o material na geladeira. Com estas precauções evitam-se erros grosseiros.

Microscopia do esfregaço: Sangue para esfregaço convém ser retirado diretamente de um corte da orelha. Os esfregaços são fixados pelo álcool metílico 5 minutos e corados por uma solução de Giemsa 1 gôta por cm3 durante 30 minutos. O corante de Giesma deve ser preparado no laboratório uma vez que em solução é pouco estável. Toma-se 0.5 do pó sêco tritura-se em gral com $33 \mathrm{~cm} 3$ de glicerina e leva-se à estufa a $55-60 .^{\circ}$ onde se deixa durante 2 horas para se obter a completa dissolução. A permanência na estufa é indispensável. Juntar depcis $33 \mathrm{~cm} 3$ de álcool metílico. Desta solução final usar uma gôta em $1 \mathrm{~cm} 3$ de água destilada neutra. A água usada para a solução deve ser neutra ou ligeiramente alcalina. Nesse sentido a água da torneira é preferivel à água destilada não verificada quanto ao $\mathrm{pH}$. A contagem de normoblastos e hemátias com restos nucleares é feita em relação às outras hemátias, tendo $\mathrm{c}$ cuidado de examinar diferentes regiões da lâmina pois quase tôdas células do sangue tem uma tendência a se localizar em determinadas zonas do esfregaço.

Diâmetro médio da hemátia: O diâmetro médio da hemátia é determinado pelo eritrocitômetro de Bock, aparelho cuja construção é baseada na difração que sofre um feixe de luz ao atravessar um filme contendo numerosas partículas $(10$ e 11). Não é aparelho de precisão porém fornece uma indicação prática e rápida de tendência à aumento ou diminuição do diâmetro médio da hemátia. Em clínica humana uma leitura acima de 7,8 (números em vermelho da escala do aparêlho) indica com segurança tratar-se de caso apresentando macrocitose, meio útil de orientação clínica quanto ao diagnóstico de anemia perniciosa de BIERMER.

\section{DETERMINAÇÃO DO VOLUME DE PLAQUETAS}

Os métodos que recomendam contagem de plaquetas pela observação direta das mesmas tanto a fresco como depois de coradas, são penosos de se executar com a necessária precisão. Ao contrário, a determinação do volume de plaquetas em $100 \mathrm{~cm} 3$ de sangue descrito por VAN AlleN (12) constitui método prático.

As limitações a êste último método referem -se a que o volume individuai de cada plaqueta varia nas diversas discrasias sanguineas e nos diferentes animais e a impossibilidade de se obter tôdas as plaquetas por centrifugação fracionada. 
A primeira objeção tem pouco valor quando se trata de experiências similares em uma mesma espécie animal.

Com efeito, quando se provoca trombocitopenia, interessa é acompanhar a diminuição gradativa até o seu desaparecimento prático da circulação. Tomando-se as precauções que serão assinaladas, temos conseguido a separação das plaquetas de maneira pràticamente satisfatória, indicada pela constância dos resultados, quando verificado o volume dêsses elementos no mesmo animal em diferentes dias.

Método. E' a modificação de Tocantins (13) ao primitivo método de Van Allen. Tomam-se $6 \mathrm{~cm} 3$ de uma solução a $3,8 \%$ de citrato de sódio adicionada de $0,1 \mathrm{~cm} 3$ de formol a $40 \%$ numa seringa com êmbolo de metal, punciona-se a veia e aspiramrse $4 \mathrm{~cm} 3$ de sangue. Agita-se para tornar homogênea a mistura e coloca-se o liquido imediatamente depois em tubo de centrifugação parafinado. Centrifuga-se para separar as hemátias e leucocitos das plaquétas. Esta operação é a mais delicada do método. Tendo a centrifugação a finalidade única de separar as hemátias e leucocitos, ela deve ser feita em tempo variável com o diâmetro do tubo e o hematocrito do sanglie. Sangue normal (com hematocrito em tôrno de $40 \%$ ) em tubo de $2,5 \mathrm{~cm}$ de diâmetro a centrifugação necessária é de 1500 rotações por minuto de 2 a 3 minutos. E' aconselhável verificar depois de 1 minuto de centrifugação se esta já foi suficiente, deixando-se mais $1 / 2$ a 1 minuto no caso contrário. Considera-se o ótimo de centrifugação aquêle tempo suficiente para que haja deposição de hemátias e leucocitos permanecendo ligeiramente roseo o sobrenadante pela presença de algumas hemátias. Uma das críticas ao método é que grande número de plaquetas na primeira centrifugação deposita-se na câmara inferior. Entretanto, isto só se dá em centrifugações excessivas quando a câmara superior se apresenta clara, pràticamente já sem hemátias. Não só servem estas hemátias sobrenadantes como indicadoras do ponto suficiente de centrifugação como também servem, no segundo tempo, para formar fundo no trombocitocrito, facilitando dessa forma a leitura da câmara de plaquetas. A seguir aspiram-se $5 \mathrm{~cm} 3$ do sobrenadante com pipeta parafinada e colocam-se no trombocitocrito. Centrifuga-se a 3500 - 4000 rotações $1 \frac{1}{2}$ horas. Com 5 minutos de centrifugação obtemrse já uma nitida separação entre as camadas de hemátias e plaquetas e têm-se a "grosso modo" uma impressão do resultado que será obtido. A leitura é diretamente feita na escala do tubo capilar do trombocitocrito. Cada intervalo corresponde a $0.05 \mathrm{de} \mathrm{cm} 3$. $O$ resultado será dividido por 2 (visto que em $5 \mathrm{~cm} 3$ do sobrenadante existem 
as plaquetas de $2 \mathrm{~cm} 3$ de sangue) e expresso em décimos de centímetro cúbico por $100 \mathrm{~cm} 3$ de sangue. Assim se a leitura foi de 50 (ou sejam 10 traços do tubo capilar) o resultado será $\frac{0.50 \mathrm{~cm} 3}{2}$ ou sejam $0.25 \mathrm{~cm} 3$ por $100 \mathrm{~cm} 3$ de sangue.

VOlume De SANGue: A técnica usada é a de Heilmeyer (14), empregando vermelho vital em vez de vermelho congo.

Com uma agulha de $30 \times 12$ punciona-se a jugular, retirando-se $10 \mathrm{~cm} 3$ de sangue em seringa perfeitamente sêca; conserva-se a agulha na veia e injeta-se uma determinada quantidade de solução de corante dissolvida em sôro fisiológico a $8.5 \%$ oo de sorte a perfazer volume idêntico ao da amostra de sangue retirada. A quantidade de vermelho vital a empregar depende do pêso do cão. A solução é de $1 \%$ de vermelho vital em água destilada. Cães até 5 quilos $2 \mathrm{~cm} 3$, de 5 a 10 quilos $3 \mathrm{~cm} 3$; de 10 a $15,4 \mathrm{~cm} 3$ e de 15 a 20 , $5 \mathrm{~cm} 3$. Deve-se ter o cuidado de injetar lentamente tôda a quantidade do corante levando-se a seringa 2 a 3 vêzes com o sangue do animal. Colocase na agulha deixada na veia um mandaril perfeitamente justo à sua luz. Decorridos 5 minutos contados do início da injeção, retira-se o mandaril colhendo-se $4 \mathrm{~cm} 3$ de sangue. Ambas as porções do sangue são colocadas em garrafas contendo oxalato em pó. A primeira porção de sangue é separada em duas partes: $1 \mathrm{~cm} 3$ para determinação de 4 micro hematócritos de VAN Allen e os $9 \mathrm{~cm} 3$ restantes são centrifugados e retirada tôda quantidade de plasma possivel que deverá estar claro sem qualquer traço de hemólise, $1,8 \mathrm{~cm} 3$ de plasma mistura-se a $0,2 \mathrm{~cm} 3$ de uma solução de vermelho vital a $0.1 \%$ (solução padrão). Com comparação prepara-se uma solução de 1.8 de plasma e 0.2 de água destilada. Lê-se a extinção entre duas soluções colocadas em cuba de $2,5 \mathrm{~mm}$ com filtro 6(S50) no espectrofotômetro de PuLFRICH. Chamaremos a extinção desta primeira leitura $\mathrm{E}_{\mathrm{s}}$. Com o plasma restante completa-se uma cuba de $2.5 \mathrm{~mm}$. A 2. ${ }^{\mathrm{a}}$ amostra de sangue é centrifugada e o plasma corado retirado o mais completamente possivel e colocado em cuba de $2.5 \mathrm{~mm}$. A 2. ${ }^{\text {a }}$ leitura é feita comparando-se esta cuba contendo o plasma normal. A extinção desta $2 .^{a}$ leitura chamaremos $E_{\mathrm{K}}$. O cálculo é feito pela fórmula abaixo:

Vol. total de plasma $(\mathrm{cm} 3)=\frac{E_{\mathrm{K}} \times \mathrm{V} \times 100}{E_{s}}$ sendo $\mathrm{V}$ o número de cm3 da sol. de vermelho vital injetada no animal. Volume total de sanguc 
$(\mathrm{cm} 3)=$ Plasma total $(\mathrm{cm} 3) \times \frac{100}{100-\text { Hematócrito }}$. Um dado que serve para controlar "a grosso modo" o resultado do volume de sangue é a relação. ST ( litros ) $\times 100$ Peso corpo (quilos)

O valor numérico deve ser $10 \pm 2$. aconselhando-se o abandono de resultados diferentes dêsses valores.

Como a base do método é a comparação da extinção do plasma antes e depois de injetado o corante. pode-se repetir a determinação mesmo que se não tenha eliminado completamente o corante da circulação.

Em cães normais com o plasma claro a determinação de contrôle da mistura dêste plasma a uma quantidade fixa do corante pode ser evitada, pois é pràticamente igual em todos os cães. Com as condições acima referidas essa extinção é igual a 0,56. Evitando-se essa operação, temrse a vantagem de retirar $4 \mathrm{~cm} 3$ de sangue na colheita da primeira amostra, o que equivale a importante economia de sangue do animal quando se tem de repetir várias vêzes êste tipo de determinação.

Em cães anêmicos, por conseqüência de hematócrito baixo, as quantidades de sangue retiradas antes e depois de injetado o corante podem ser diminuídas para $2 \mathrm{~cm} 3$ cada amostra em vista do maior rendimento do plasma.

Um detalhe importante nesta determinação consiste em deixar a agulha com um mandril perfeitamente ajustado no tempo que decorre entre a colheita das duas amostras de sangue. Assim se evita puncionar repetidas vêzes a veia e eventua atraso na colheita da segunda amostra.

CôR do Plasma : Empregamos a técnica de Heilmeyer (15).

O plasma proveniente de sangue retirado em jejum é colocado em cuba de $10 \mathrm{~mm}$ de espessura para sangues normais e em espessuras mais reduzidas $(5 \mathrm{a} 1 \mathrm{~mm}$ ) para plasma ictéricos. Usa-se o fitro azul ( $\mathrm{S} \mathrm{47)} \mathrm{tomando}$ água destilada como líquido de compensação. O cálculo é o seguinte: multiplica-se a extinção encontrada por 10 e divide-se pela espessura da cuba empregada $(\mathrm{mm})$. A côr do sôro varia paralelamente à taxa de bilirubina.

Sua determinação nos dá, pois, um valor relativo muito útil quanto ao conteúdo de bilirubina no plasma. 
DETERMINAÇÃO DOS ELEMENTOS DA SÉRIE BRANCA: Dilue-se o sangue a 1 para 20 em pipeta de THома especialmente calibrada para essa contagem. usando-se como líquido diluidor uma solução a $5 \%$ de ácido acético em água destilada, à qual se pode adicionar $2 \mathrm{~cm} 3$ de solução a $0.5 \%$ de azul de toluidina ou azul de metileno para tornar mais aparentes os núcleos dos leucócitos. Agitarse demoradamente e coloca-se na câmara de Neubauter. Contam-se os quatro quadrados laterais de $1 \mathrm{~mm} 2$ de superfície contendo 16 quadradinhos. Na prática é suficiente tirar a média do número de leucócitos em cada quadrado e multiplicar por duzentos.

Tira--se a média de leucócitos por quadrado de $1 \mathrm{~mm}^{2}$ de superfície, multiplica-se por 10 para se obter milimetro cúbico. Tratando-se de acentuada leucopenia ou leucocitóse elevada (leucemias, por ex.), faz-se uma diluição menor ou maior utilizando as subdivisões apresentadas no capilar da pipeta. Um contrôle dessa determinação pode ser feita por meio do hematócrito, como já referimos ao falar sôbre êstes aparelhos.

\section{RESULTADOS}

Em 135 cães adultos (100 machos e 35 fêmeas) foi determinado o número de hemátias, o hematócrito e dosada hemoglobina e desses resultados calculados os índices qualitativos médios da hemátia. Os dados obtidos estão reunidos na tabela 1 em que estão assinalados os valores médios, o desvio padrão e o desvio padrão da média do grupo de animais machos, do grupo de fêmeas e do grupo combinado. Nenhuma diferença estatisticamente significativa foi observada em relação ao sexo, confirmando assim as verificações de vários outros autores.

TABELA I

\begin{tabular}{|c|c|c|c|c|c|c|}
\hline & \multicolumn{2}{|c|}{ MACHOS } & \multicolumn{2}{|c|}{ FÊMEAS } & \multicolumn{2}{|c|}{ GRUPO COMBINADO } \\
\hline & $M \pm D . P$ & Sigma & $\mathrm{M} \pm \mathrm{D} . \mathrm{P}$ & Sigma & $\mathrm{M} \pm \mathrm{D} . \mathrm{P}$ & Sigma \\
\hline Hematias (milhões por $\mathrm{mm} 3$ ). & $5.7 \pm .061$ & .615 & $5.8 \pm .103$ & .612 & $5.7 \pm .053$ & .620 \\
\hline Hemoglobina (g/100 $\mathrm{cm} 3$ sangue)... & $12.60 \pm .128$ & 1.28 & $12.60 \pm .244$ & 1.42 & $12.60 \pm .108$ & 1.26 \\
\hline Hematócrito $(\%) \ldots \ldots \ldots$ & $42 \pm .560$ & 5.60 & $42 \pm .950$ & 5.70 & $42 \pm .485$ & 5.65 \\
\hline Indice de volume $\left(\mu^{3}\right) \ldots$ & $74 \pm .310$ & 3.10 & $74 \pm .646$ & 3.88 & $74 \pm .344$ & 4.00 \\
\hline Indice de Hemoglobina $(\gamma \gamma)$.. & $22 \pm .119$ & 1.19 & $22 \pm .169$ & 1.00 & $22 \pm .101$ & 1.17 \\
\hline Indice de saturação $(\%)$. & $30 \pm .185$ & 1.85 & $31 \pm .342$ & 2.42 & $30 \pm .162$ & 1.88 \\
\hline
\end{tabular}


$\mathrm{Na}$ tabela 2 estão reunidos os valores encontrados por vários autores, observando-se valores médios ligeiramente inferiores aos assinalados pela maioria dos pesquisadores.

TABELA 2

\begin{tabular}{|c|c|c|c|c|c|c|c|}
\hline AUTOR & $\begin{array}{l}\text { NÚMERO } \\
\text { ANIMAIS }\end{array}$ & $\begin{array}{l}\text { HEMATIAS } \\
\left(10^{6} / \mathrm{mm}^{3}\right)\end{array}$ & $\begin{array}{c}\text { HEMOGLOBINA } \\
\text { (g/100 } \mathrm{cm}^{3} \\
\text { san:sue) }\end{array}$ & $\begin{array}{c}\text { HEMATó- } \\
\text { CRITO } \\
(\%)\end{array}$ & $\begin{array}{c}\text { ÍNDICE } \\
\text { VOLUME } \\
\left(\mu^{3}\right)\end{array}$ & $\begin{array}{c}\text { ÍNDICE } \\
\text { HEMOGLO- } \\
\text { BINA }(Y Y)\end{array}$ & $\begin{array}{l}\text { INDICE } \\
\text { SATURACÃOO } \\
(\%)\end{array}$ \\
\hline 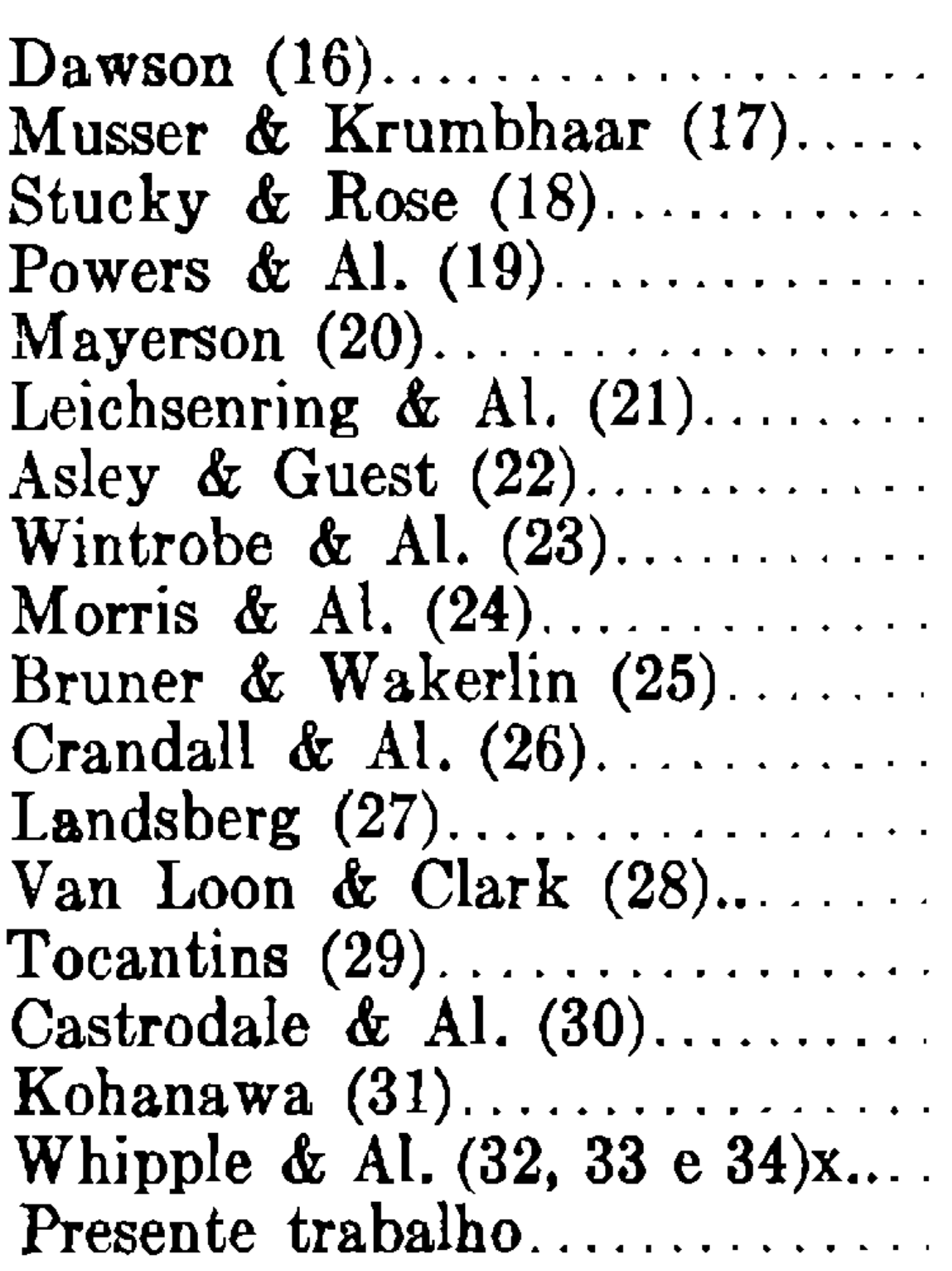 & $\begin{array}{r}15 \\
47 \\
12 \\
25 \\
60 \\
32 \\
50 \\
54 \\
31 \\
34 \\
25 \\
66 \\
81 \\
53 \\
12 \\
12 \\
27 \\
135\end{array}$ & $\begin{array}{l}7.22 \\
5.97 \\
7.00 \\
6.49 \\
7.17 \\
6.87 \\
7.02 \\
6.20 \\
6.45 \\
6.20 \\
6.27 \\
6.20 \\
6.13 \\
6.47 \\
6.2 \\
5.8 \\
5.7\end{array}$ & $\begin{array}{l}11.9 \\
15.5 \\
15.0 \\
15.8 \\
13.0 \\
14.1 \\
16.0 \\
14.6 \\
15.1 \\
13.5 \\
12.9 \\
13.9 \\
14.5 \\
13.5 \\
- \\
15.8 \\
12.6\end{array}$ & $\begin{array}{c}- \\
\overline{-} \\
45.2 \\
38.6 \\
47.7 \\
45.6 \\
47.3 \\
\overline{44.2} \\
- \\
44.2 \\
45.6 \\
- \\
- \\
44.0 \\
42.0\end{array}$ & $\begin{array}{c}- \\
- \\
64.5 \\
59.3 \\
66.5 \\
66.6 \\
67.6 \\
- \\
68.9 \\
71.3 \\
70.5 \\
73.4 \\
- \\
- \\
76.0 \\
74.0\end{array}$ & $\begin{array}{c}26.0 \\
- \\
- \\
23.6 \\
20.0 \\
19.7 \\
23.6 \\
21.2 \\
24.3 \\
21.3 \\
20.9 \\
21.8 \\
23.7 \\
- \\
- \\
- \\
27.0 \\
22.0\end{array}$ & $\begin{array}{c}- \\
\overline{-} \\
35.0 \\
34.3 \\
29.6 \\
39.4 \\
31.4 \\
- \\
30.7 \\
- \\
32.3 \\
32.3 \\
- \\
- \\
36.0 \\
30.0\end{array}$ \\
\hline
\end{tabular}

x Médias dos valores citados nos trabalhos consultados.

Na tabela 3 foram reunidos dados obtidos na determinação do volume total de sangue de 42 cães, usando-se o método de coloração do plasma. O volume total de sangue variou entre $10.3 \% \pm 3.3$ do pêso corpóreo; a hemoglobina circulante entre $10.7 \% \pm 3.2$ e o volume total de plasma entre $5.9 \% \pm 1.8$ ambos êsses resultados também em relação ao pêso do corpo.

Em 100 cães o número de leucócitos foi de $12.200 \pm 7.000$ por $\mathrm{mm} 3$; o diâmetro médio da hemátia pelo eritrocitometro de Bock foi de $6.9 \pm 0.4 \mathrm{e}$ a percentagem de reticulocitos variou entre 0.1 e $1.5 \%$.

$O$ volume de plaquetas determinado em 42 cães foi de $0.60 \pm 0.35 \mathrm{~cm} 3$ por $100 \mathrm{~cm} 3$ de sangue. 


\begin{tabular}{|c|c|c|c|c|c|c|c|c|c|c|}
\hline N.o & SEXO & $\begin{array}{c}\text { PÉSO } \\
\text { DO CORPO } \\
(k s)\end{array}$ & $\begin{array}{l}\text { HEMATó- } \\
\text { CRITO } \\
(\%)\end{array}$ & $\begin{array}{l}\text { HEMOGLOBINA } \\
\left(\mathrm{g} / 100 \mathrm{~cm}^{3}\right)\end{array}$ & $\begin{array}{c}\text { VOLUME } \\
\text { DO PLASMa } \\
\left(\mathrm{cm}^{3}\right)\end{array}$ & $\begin{array}{c}\text { VOL, SANGUE } \\
\text { TOTAL } \\
\left(\mathrm{cm}^{3}\right)\end{array}$ & $\begin{array}{c}\text { HEMOGLOBINA } \\
\text { CIRCULANTE } \\
\text { (g) }\end{array}$ & $\begin{array}{c}\text { RELAÇ̃̃o } \\
\frac{\text { V. P. }}{\text { PÊSO }}\end{array}$ & $\begin{array}{c}\text { RELAÇ̃̃OO } \\
\frac{\text { V.T. }}{\text { PÊSO }}\end{array}$ & $\begin{array}{l}\text { RELAÇ̃̃o } \\
\text { Hb. Circ. } \\
\text { PÉSO }\end{array}$ \\
\hline $\begin{array}{r}110 \\
71 \\
22 \\
20 \\
12 \\
10 \\
82 \\
79 \\
80 \\
89 \\
98 \\
76 \\
86 \\
100 \\
102 \\
103 \\
104 \\
105 \\
119 \\
121 \\
125 \\
126 \\
154 \\
251 \\
250 \\
245 \\
246 \\
247 \\
15 \\
11 \\
9 \\
222 \\
223 \\
254 \\
257 \\
260 \\
259 \\
255 \\
256 \\
253 \\
258 \\
262\end{array}$ & 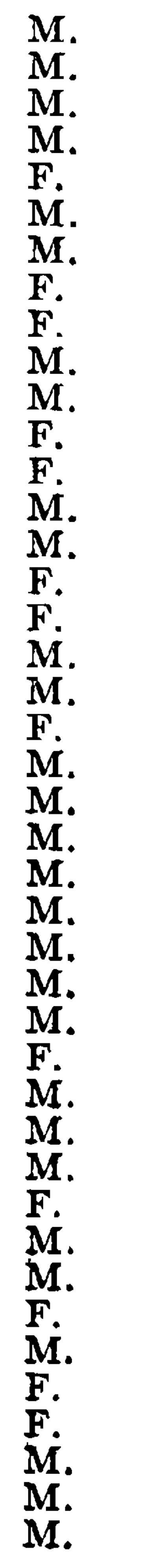 & $\begin{array}{r}11.5 \\
5.5 \\
5.5 \\
6.5 \\
9.0 \\
8.7 \\
5.3 \\
3.8 \\
6.3 \\
3.6 \\
7.0 \\
4.5 \\
6.1 \\
9.5 \\
8.7 \\
10.0 \\
7.2 \\
9.5 \\
8.6 \\
10.5 \\
4.6 \\
6.4 \\
11.4 \\
10.5 \\
8.0 \\
8.9 \\
7.1 \\
9.6 \\
5.9 \\
6.0 \\
5.2 \\
9.0 \\
7.0 \\
9.1 \\
7.9 \\
5.1 \\
10.7 \\
9.7 \\
9.7 \\
13.5 \\
13.3 \\
12.1\end{array}$ & $\begin{array}{l}48 \\
48 \\
38 \\
36 \\
36 \\
34 \\
41 \\
38 \\
58 \\
35 \\
44 \\
35 \\
35 \\
43 \\
41 \\
34 \\
49 \\
42 \\
40 \\
38 \\
38 \\
48 \\
36 \\
47 \\
47 \\
34 \\
43 \\
43 \\
39 \\
39 \\
39 \\
40 \\
40 \\
50 \\
46 \\
38 \\
33 \\
45 \\
44 \\
50 \\
47 \\
46\end{array}$ & $\begin{array}{l}13.50 \\
14.25 \\
11.75 \\
10.75 \\
11.25 \\
10.75 \\
12.00 \\
11.00 \\
15.50 \\
10.50 \\
13.00 \\
10.25 \\
10.00 \\
13.00 \\
12.00 \\
10.50 \\
15.00 \\
12.00 \\
12.25 \\
12.00 \\
11.75 \\
14.00 \\
10.75 \\
13.25 \\
12.50 \\
11.00 \\
11.75 \\
12.00 \\
11.75 \\
12.00 \\
12.75 \\
13.00 \\
12.50 \\
13.00 \\
12.25 \\
11.75 \\
11.75 \\
12.00 \\
11.75 \\
14.00 \\
12.75 \\
12.00\end{array}$ & $\begin{array}{l}480 \\
285 \\
414 \\
430 \\
562 \\
666 \\
259 \\
220 \\
311 \\
249 \\
296 \\
345 \\
374 \\
545 \\
510 \\
620 \\
374 \\
600 \\
450 \\
460 \\
295 \\
362 \\
740 \\
445 \\
382 \\
620 \\
420 \\
600 \\
407 \\
462 \\
382 \\
450 \\
370 \\
495 \\
400 \\
304 \\
670 \\
670 \\
525 \\
700 \\
700 \\
607\end{array}$ & $\begin{array}{r}925 \\
520 \\
666 \\
671 \\
829 \\
1010 \\
455 \\
355 \\
740 \\
383 \\
530 \\
515 \\
575 \\
960 \\
865 \\
940 \\
705 \\
1020 \\
750 \\
740 \\
475 \\
700 \\
1154 \\
840 \\
720 \\
930 \\
735 \\
1020 \\
668 \\
740 \\
626 \\
750 \\
620 \\
990 \\
740 \\
490 \\
1000 \\
1220 \\
940 \\
1400 \\
1320 \\
1120\end{array}$ & $\begin{array}{r}104 \\
65 \\
70 \\
65 \\
85 \\
98 \\
48 \\
35 \\
96 \\
36 \\
60 \\
48 \\
52 \\
110 \\
92 \\
89 \\
92 \\
108 \\
82 \\
79 \\
50 \\
85 \\
112 \\
97 \\
78 \\
94 \\
76 \\
108 \\
70 \\
79 \\
71 \\
87 \\
69 \\
111 \\
79 \\
51 \\
107 \\
128 \\
97 \\
170 \\
146 \\
117\end{array}$ & $\begin{array}{l}4.2 \\
5.2 \\
7.5 \\
7.0 \\
6.2 \\
7.0 \\
5.6 \\
5.8 \\
4.9 \\
6.9 \\
4.2 \\
7.7 \\
6.1 \\
5.7 \\
5.9 \\
6.2 \\
5.2 \\
6.2 \\
5.2 \\
4.9 \\
6.4 \\
5.7 \\
6.5 \\
4.2 \\
4.8 \\
7.0 \\
5.9 \\
6.2 \\
6.9 \\
7.7 \\
7.3 \\
5.0 \\
5.3 \\
5.4 \\
5.1 \\
6.0 \\
6.3 \\
6.9 \\
5.4 \\
5.2 \\
5.3 \\
5.0\end{array}$ & $\begin{array}{r}8.1 \\
9.5 \\
12.0 \\
10.9 \\
9.1 \\
11.7 \\
8.5 \\
9.4 \\
11.7 \\
10.4 \\
7.6 \\
11.6 \\
9.5 \\
10.1 \\
9.9 \\
9.4 \\
9.9 \\
10.1 \\
8.6 \\
7.0 \\
10.3 \\
11.0 \\
10.1 \\
8.0 \\
8.9 \\
10.4 \\
10.3 \\
10.6 \\
11.4 \\
12.1 \\
11.9 \\
8.2 \\
7.0 \\
10.9 \\
9.3 \\
9.4 \\
9.3 \\
12.6 \\
9.6 \\
10.4 \\
9.8 \\
9.2\end{array}$ & $\begin{array}{r}9.0 \\
11.8 \\
12.7 \\
10.6 \\
9.4 \\
11.2 \\
9.0 \\
9.2 \\
15.2 \\
10.0 \\
8.6 \\
10.6 \\
8.5 \\
11.6 \\
10.5 \\
8.9 \\
12.8 \\
11.3 \\
9.5 \\
7.5 \\
10.8 \\
13.3 \\
9.8 \\
9.2 \\
9.7 \\
10.5 \\
10.7 \\
11.2 \\
11.9 \\
13.1 \\
13.6 \\
9.6 \\
9.8 \\
12.2 \\
10.0 \\
10.0 \\
10.0 \\
13.2 \\
10.0 \\
12.6 \\
11.0 \\
9.7\end{array}$ \\
\hline
\end{tabular}




\section{RESUMO}

Os AA. apresentam o resultados das cifras hemáticas e cutros dados hematologicos de cães adultos, normais e descrevem as várias técnicas empregadas.

Agradecemos ao Serviço de Assistência Veterinária da Prefeitura do Distrito Federal a remessa de cães para nossos trabalhos.

\section{SUMMARY}

The results of study on the blood picture of 135 mature normal mongrels (100 male and 35 female) are presented.

The values found for the red blood cell are:

\begin{tabular}{|c|c|c|c|c|c|c|}
\hline \multirow[t]{2}{*}{ ' } & \multicolumn{2}{|c|}{ MALE GROUP } & \multicolumn{2}{|c|}{ FEMALE GROUP } & \multicolumn{2}{|c|}{ COMBINED GROUPS } \\
\hline & $M \pm \mathrm{S} . \mathrm{D}$ & Sigma & $\mathbf{M} \pm \mathrm{S} . \mathrm{D}$ & Sigma & $\mathrm{M} \pm \mathrm{S} . \mathrm{D}$ & Sigma \\
\hline Er.ythrocytes $\left(10^{6} / \mathrm{c} . \mathrm{mm}\right)$ & $5.7 \pm .061$ & .615 & $5.8 \pm .103$ & .612 & $5.7 \pm .053$ & .620 \\
\hline Hemoglobin $(\mathrm{gm} \%)$ & $12.60 \pm .128$ & 1.28 & $12.60 \pm .244$ & 1.42 & $12.60 \pm .108$ & 1.26 \\
\hline Hematocrit $(\%) \ldots$ & $42 \pm .560$ & 5.60 & $42 \pm .950$ & 5.70 & $42 \pm .485$ & 5.65 \\
\hline $\begin{array}{l}\text { Volume Index (Mean corpuscular vo- } \\
\quad \text { lume })\left(\mu^{3}\right\} \ldots \ldots \ldots \ldots \ldots \ldots\end{array}$ & $74 \pm .310$ & 3.10 & $74 \pm .646$ & 3.88 & $74 \pm .344$ & 4.00 \\
\hline $\begin{array}{l}\text { Henoglobin indext(Mean corpuscular } \\
\text { hemoglobin })(\gamma \gamma \gamma) \ldots \ldots \ldots \ldots \ldots\end{array}$ & $22 \pm .119$ & 1.19 & $22 \pm .169$ & 1.00 & $22 \pm .101$ & 1.17 \\
\hline $\begin{array}{l}\text { Saturation Index (Mean corpuscular } \\
\text { hemoglobin concentration) }(\%) \ldots\end{array}$ & $30 \pm .185$ & 1.85 & $31 \pm .342$ & 2.42 & $30 \pm .162$ & 1.88 \\
\hline
\end{tabular}

The blood volume was determined by the dye method in 42 dogs. The ratio total blood volume/body weight $: 10.3 \% \pm 3.3$; the ratio hemoglogin body weight $: 10.7 \% \pm 3.2$ and the ratio Plasma volume/body weight : $5.9 \% \pm 1.8$. The mean erythrocyte diameter by Bock's erythrocytometer : $6.9 \pm 0.4$ micra. The variation of reticulocytes $: 0.1$ to $1.5 \%$.

The platelet volume determined by thrombocy tocrit method in 42 dogs: $0.60 \pm 0.30 \mathrm{c} . \mathrm{cm}$ per $100 \mathrm{c} . \mathrm{cm}$.

The leucocytes in 100 animals : $12.200 \pm 7.800$ per c. mm.

No difference between the male and female group was verified in accordance with observations of other authors. 


\section{BIBLIOGRAFIA}

1) NewCOMER, H.

1919. J. Biol. Chem.. 37; 465.

2) Heilmeyer, L. E Sundermam, A.

1936. Deuts. Arch. Klin. Med., $178: 397$.

3) WONG, S. Y.

1928. J. Biol. Chem., $77: 409$.

4) Wintrobe, M. M.

1942. Clinical Hematology. Lea E Febiger, Philadelphia, pg. 72.

5) Van Allen, C. M.

1924/25. J. Lab. Clin. Med., $17: 899$.

6) Wintrobe, M. M.

1932. J. Lab. E Clin. Med., $17: 899$.

7) PaNder, E.

1934. Protoplasma Monographiem, Berlim, Gebrueder Borntraeger $6: 2$.

8) Hunter, F. T.

1940. J. Clin. Inv., $19: 691$.

9) Whitby, L. E. H. E Hynes, M.

1935. J. Path. E Bact. $40: 219$.

10) Pijper. A.

1919. M. J. South Africa, $14: 472$.

11) Bock, H. E.

1933. Klin. Wchusche., $12: 1141$.

12) Van Allen, C. M.

1926/27. J. Lab. \& Clin. Med., $12: 282$.

13) Tocantins, L. M.

1937. Arch. Path., $23: 850$.

14) Heilmeyer, L.

1929. Biochem. Z., $212: 430$.

15) Heilmeyer, L.

1928. Z. ges. exp. Med., $63: 632$.

16) Dawson, P. M.

1900. Am. J. Physiol., $4: 1$.

17) Musser, Jl H. E Krumbhaar, E. B.

1914. Folia Haematol., $18: 576$.

18) Stucky, C. J. e Rose, W. B.

1929. Am. J. Physiol., $89: 1$.

19) Powers, J. H., Bowie, M. A. E Howard, I. M.

1930. Am. J. Physiol. $92: 665$.

20) Mayerson, H. S.

1930. Anat. Rec., $47: 239$.

21) Leichserning, J. M. $\mathcal{E}$ al.

1932. Am. J. Physiol., $99: 391$. 
22) Asley, A. e Guest, G. M.

1934. J. Clin. Insvest., $13: 219$.

23.) Wintrobe, M. M. E col.

1936. Am. J. Physiol., $114: 502$.

24) MarrRis, M. L. E col.

1940. J. Lab. \& Clin. Med., 25 : 353.

25) Bruner, H. D. E Wakerlin, G. E.

1937. Proc. Soc. Exp. Biol. \& Med. $36: 667$.

26) Crandall Jr., L. A., Finne JR., C. O., E Smith, P. W.

1941. Science, $93: 549$.

27) LANDSBERG, J. 'W.

1942. Anat. Rec., 84: 415.

28) Van Loon, E. J., Clark, B. B.

1943. J. Lab. E Clin. Med. 28 : 575.

29) Tocantins, L. M.

1936. An. of Int. Med., $9: 838$.

30) Castrodale, D. E col.

1941. Endecrinology, $29: 363$.

31) Kohanawa, C.

1928. Folia Haemat. $36: 174$.

32) Whipple, G. H. \& col.

1921. Am. J. Phys., $56: 336$.

33) HahN, P. F. E col.

1941. Science, $93: 87$.

34) Cruz, W. O.

1941. Am. J. Med. Sci. $202: 781$. 